\title{
How Effective Altruism Can Help Psychologists Maximize Their Impact
}

Izzy Gainsburg ${ }^{1}$, Shiva Pauer $^{2}$, Nawal Abboub $^{3}$, Eamon T. Aloyo ${ }^{4}$, Jean-Christophe Mourrat ${ }^{5}$,

\author{
Alejandrina Cristia ${ }^{6}$ \\ ${ }^{1}$ Ross School of Business, University of Michigan \\ ${ }^{2}$ Department of Social Psychology, University of Amsterdam \\ ${ }^{3}$ RisingUp \\ ${ }^{4}$ Institute for Security and Global Affairs, Leiden University \\ ${ }^{5}$ Courant Institute of Mathematical Sciences, New York University \\ ${ }^{6}$ Laboratoire de Sciences Cognitives et de Psycholinguistique, \\ Département d'études cognitives, ENS, EHESS, CNRS, PSL University
}

\section{Author Note}

IG acknowledges the Ross School of Business. AC acknowledges the Agence Nationale de la Recherche (ANR-17-EURE-0017); and the J. S. McDonnell Foundation Understanding Human Cognition Scholar Award. We are grateful to colleagues in the MPI's Dept of Comparative Cultural Psychology, Jason Schukraft, and Julia Lee Cunningham for feedback on previous versions; and Yabelis de la Rosa for help with the references and Figure 1. We have no known conflict of interests to disclose.

Correspondence concerning this article should be addressed to Izzy Gainsburg, Ross School of Business, 701 Tappan Avenue, University of Michigan, Ann Arbor, MI 48109. Contact:

$\underline{\operatorname{izzyg} @ \text { umich.edu }}$ 


\begin{abstract}
Although many psychologists are interested in making the world a better place through their work, they are often unable to have the impact that they would like. Here, we suggest that both individuals and psychology as a field can better improve human welfare by incorporating ideas from Effective Altruism, a growing movement whose members aim to do the most good by using science and reason to inform their efforts. In this paper, we first provide a brief introduction to Effective Altruism and review important principles that can be applied to how psychologists approach their work, such as the ITN framework (Importance, Tractability, and Neglectedness). Next, we review how effective altruism can inform individual psychologists' choices. Finally, we close with a discussion of ideas for how psychology, as a field, can increase its positive impact. By applying insights from effective altruism to psychological science, we aim to integrate a new theoretical framework into psychological science, stimulate new areas of research, start a discussion on how psychology can maximize its impact, and inspire the psychology community to do the most good.
\end{abstract}


Psychologists often want to help others and make the world a better place through their work (Farber et al., 2005; Huynh \& Rhodes, 2011; Stewart et al., 2005). And yet, we do not achieve this goal as often as we would like (Barlow, 2010; Osman et al., 2020). In this paper, we argue that psychologists can better accomplish their goal of having a positive impact on the world by considering ideas from effective altruism (EA), a social movement and philosophy about "doing good better." In what follows we provide a brief overview of EA and suggest how EA can inform individual psychologists and the field as a whole.

\section{Introduction to EA}

At the broadest level, EA is a social movement of diverse people united by a common goal: finding ways to do the most good in the world with our limited resources by using high-quality evidence and careful reasoning (MacAskill, 2015; see Table 1 for additional resources).

Table 1: Notable Effective Altruism resources

\begin{tabular}{|c|c|}
\hline Resource & Title \\
\hline General audience books & $\begin{array}{l}\text { Doing Good Better by William MacAsklill; The Most Good You Can Do by } \\
\text { Peter Singer }\end{array}$ \\
\hline General information & Effective Altruism (effectivealtruism.org) \\
\hline Getting involved & https://www.effectivealtruism.org/get-involved/ \\
\hline Giving communities & $\begin{array}{l}\text { One for the world (https://www.1 fortheworld.org/); Giving what we can } \\
\text { (givingwhatwecan.org); }\end{array}$ \\
\hline Career information & 80,000 hours (80000hours.org) \\
\hline EA-aligned thesis ideas & https://effectivethesis.org/theses/?discipline=psychology\#disciplines \\
\hline EA FAQ and Criticisms & effectivealtruism.org/faqs-criticism-objections \\
\hline EA teaching resources & $\begin{array}{l}\text { https://forum.effectivealtruism.org/posts/Y8mBXCKmkS9eBokhG/ea-syllabi-a } \\
\text { nd-teaching-materials }\end{array}$ \\
\hline Advanced discussions & Effective altruism: Philosophical issues (Greaves \& Pummer, 2019) \\
\hline
\end{tabular}

\subsection{The Methods of Effective Altruism}

In EA, choosing the most impactful actions is done through evidence and reasoning. Below, we review core principles that have been reasoned to inform effective actions. 


\subsubsection{Cost-effectiveness and rational decision-making. Cost-effectiveness and} cost-benefit analyses predate EA and, in line with their usefulness in other decision-making contexts, they are central to EA efforts to take actions that have the most social impact. Comparisons of different actions often use standardized measures of welfare such as quality- or disability-adjusted life years (QALYs and DALYs; Sassi, 2006). The potential gain of selecting the most cost-effective actions is great because interventions and causes often constitute a heavy-tailed distribution, where the most impactful causes/interventions are much more cost-effective than those at the median. For instance, in an analysis of global public health interventions, the most effective interventions were 60 times more effective than those at the median and 15,000 times more effective than the least effective interventions (Ord, 2013). Similarly, Caviola and colleagues (2020) show that the most effective charities are often 100 times more effective than typical charities. When costs and benefits are difficult to estimate, many in EA turn to other tools for rational decision-making, including expected value estimations, Fermi estimates, and logical reasoning (e.g., Greaves \& MacAskill, 2019).

\subsubsection{Cause prioritization and the importance, tractability, neglectedness (ITN)}

framework. More broadly, effective altruists consider which causes are likely to be the most impactful to address through cause prioritization research. Cause prioritization entails judgments with less measurable and certain costs and benefits, as compared to comparing the cost-effectiveness of specific interventions with concrete outcomes. Such evaluations and comparisons require one to employ a different process to identify the most effective actions. MacAskill (2015) has therefore introduced an adapted estimation of expected value as a function of the cause's importance, tractability, and neglectedness (i.e., the ITN framework; see also Wiblin, 2016). Importance refers to the size of the problem (e.g., how many lives does this 
problem affect, and how severe is that effect?). Neglectedness refers to whether the problem is relatively neglected versus oversaturated; given the potential for diminishing marginal returns, investments in problems that are already attracting a great deal of resources will typically be less impactful than investments in problems that are relatively neglected. Finally, tractability refers to the idea that it is more impactful to invest in causes where one can plausibly make more progress on the issue at hand.

2.2.3 Impartiality and cause-neutrality. In EA, it is a common belief that people should be impartial in who they choose to help. This means not favoring people on account of dimensions such as race or nationality. For some effective altruists, this means giving significant or equal weight to unborn people in future generations and to non-human animals. Impartiality is often advocated as a normative consideration (consistent with the moral norm of fairness), but also because it can guide effective actions (i.e., being partial can interfere with having the greatest impact). For this same reason, cause prioritization often involves cause neutrality, i.e., choosing causes based on impartial estimates of impact (e.g., all else equal, we should allocate more funds to depression than Alzheimer's disease, because the former cause accounts for more of the global burden of disease; The Lancet, 2020). Many effective altruists also acknowledge that, practically, most people favor the interests of themselves and their close friends and family, and that these interests can be carefully balanced against the moral goals of being impartial and maximizing social impact (Schubert \& Caviola, 2021).

2.2.4 Diversity of causes and moral systems. Although the ITN framework has led many in EA to focus on certain causes that are now archetypal of the movement (e.g., health among the extremely poor, animal welfare, threats to human extinction), there are over a dozen issues formally recommended by leaders in EA and other important problems the EA community 
may not have considered yet $(80,000$ Hours, 2021). Thus, leaders in the movement frequently revisit their ranking of what problems are most important based on new evidence. Additionally, there is considerable acceptance of various moral frameworks within EA, consistent with the diversity of moral beliefs among leading ethicists and human cultures (see MacAskill et al., 2020 for a discussion about a framework for making decisions under moral uncertainty about which moral frameworks are correct and Supplementary Online Material [SOM] 1 for "moral position statements" from two of the authors).

2.2.5 Individual fit. People typically have a greater marginal impact when they choose jobs where they are a top performer and there are few comparable replacements. This requires one to consider their unique background, skills, and personal interests. For instance, someone with specialized knowledge about fMRI may be best suited for neuroimaging research than science outreach, given that well-trained fMRI researchers are likely in shorter supply. One's personal interest in a domain also matters for maximizing impact because it can help motivate the sustained efforts that are typically necessary to achieve impactful work outcomes.

\section{Considerations for individual psychologists}

In this section, we discuss how psychologists can do the most good in a professional capacity. For readers who are interested in increasing their positive impact at a personal level, such as recommendations for donating and opportunities for getting involved in EA, see "Getting involved" in Table 1; for recommendations about other roles psychologists may have (e.g., mentors; science communicators), see SOM 2.

Before proceeding, we note that our recommendations are not "one-size-fits-all." As mentioned earlier, how to do the most good in one's career is heavily dependent on personal fit, which includes aspects of the individual (e.g., their skills, interests, values, etc.) and the situation 
that they are in (e.g., local laws or norms that constrain behaviors; the important problems in one's community).

In addition, we do not presume that our suggestions are the best and only ways to do the most good or that every decision should be about maximizing impact. The present recommendations are derived from EA principles but involve large uncertainties. We encourage readers to critique our ideas and build on them to generate new possibilities for how psychologists can do the most good as they read the suggestions presented below.

\subsection{Teaching}

3.1.1 Considerations for what is taught. Participating in university courses can change students' moral beliefs and corresponding behaviors (Frank et al., 1996). To take an example

relevant to a popular EA cause area, Schwitzgebel and colleagues (2020) showed that discussing the morality of meat consumption in an ethics class reduced students' meat consumption (see also Jalil et al., 2020).

Similarly, if psychology teachers find organic ways to fold EA concepts into their classes, they may help students discover an interest in an important cause, decide a career based on the likelihood of high positive impacts, or motivate a lifetime of more effective giving. Below, we highlight some specific examples from common core courses for psychology undergraduates.

- Abnormal or clinical psychology: Introduce disorders in their order of prevalence and severity, and discuss neglectedness and tractability for each (see section 3.2 for clinicians).

- Social and/or cognitive psychology: Discuss literature on how well-established heuristics and biases can result in ineffective giving or the neglect of important cause areas (see Section 3.3.2 for examples). 
- Developmental or educational psychology: Introduce scalable social emotional learning programs that have been shown to be relatively effective and ineffective (Barry et al., 2013; Durlak et al., 2011).

- Positive psychology: Discuss the non-linear relationship between money and happiness, and how (above a certain income threshold) increasing one's own wealth increases one's happiness less than an equivalent charitable donation increases the happiness of someone who is extremely poor (see also Section 3.3.1).

- Statistics: Bring up the outsized impact of the best (and worst) interventions when teaching ideas about central tendency, heavy-tailed distributions, and effect sizes (Kokotajlo \& Oprea, 2020; Ord, 2013).

In addition, teachers who can choose which classes they teach could propose a class on how psychology intersects with EA (see Table 1 for EA teaching resources) or a class dedicated to how psychology intersects with a specific cause area (e.g., the psychology of human extinction risks, Schubert et al., 2019).

3.1.2 Increasing accessibility. Teachers can be more effective if they reach more people (i.e., addressing importance) or people who would otherwise not benefit from similar resources (i.e., addressing neglectedness), at a minimum by sharing their teaching material on personal websites, the Open Science Framework (e.g., Urry et al., 2018), or through online courses. For instance, psychologist Laurie Santos has offered "The Science of Well-Being” via Coursera to nearly 4 million people; people can access this high-quality course in one of 13 different languages, without financial cost (under certain conditions). Similarly, teachers can offer courses they have already prepared to new audiences, for example at pre-conference workshops and summer or winter schools, particularly those that benefit students who may not have teachers of 
that expertise in their local community (e.g., the $/ \mathrm{L}+/$ school on language acquisition, which served hundreds of students from over 70 countries; Arokoyo et al., 2021).

\subsection{Clinical work}

3.3.1 Cost-effectiveness considerations for treatment methods. Clinical psychologists often aim to identify and use the most effective treatment methods, as evidenced by articles that compare the relative effectiveness of different treatments (e.g., Castelnuovo et al., 2016) and codified guidelines for treating various issues (e.g., the DSM, American Psychiatric Association, 2013). However, it is less common to consider cost (see Castelnuovo et al., 2016 for discussion). Costs could include the resources (e.g., time or effort) required for a clinician or patient to learn a treatment.

Another cost that may not be obvious is that involved in initially learning a new therapy, and the practice necessary to become skilled at it. This is consistent with the call for transdiagnostic therapies (Schaeuffele et al., 2021), i.e., treatments that are appropriate for a range of mental health issues. By learning flexible treatment strategies, clinicians could possibly treat a wider portfolio of issues; likewise, a patient learning a flexible therapy may be better equipped to cope with emergent mental health issues if they arise. For instance, one paper suggests that repetitive negative thinking is a transdiagnostic mechanism underlying a host of mental health disorders, and that short-circuiting this process could provide benefits across a range of comorbid disorders (Ehring \& Watkins, 2008).

One final treatment-level idea for increasing cost-effectiveness is to find ways to treat more patients (while minimizing costs to time and effectiveness). In psychotherapy, the norm is often long, repeated, individualized sessions between a therapist and a patient at a clinic. Instead, clinicians could reach more people through group therapy, which can sometimes be similarly 
effective as individual therapy (McDermut et al., 2001; Wergeland et al., 2014), and they could incur lower time costs via tele-health alternatives (Hilty et al., 2013). Another example is aiming to develop scalable interventions for mental, neurological, and substance use (MNS) disorders, consistent with recommendations from the World Health Organization and the Disease Control Priorities Study (DCP-3; Patel et al., 2016). For instance, Jessica Schleider deploys web-based, single-shot mental health interventions for adolescent populations that lack access to treatment and have high rates of drop-out in more traditional programs (Schleider et al., 2020; Schleider \& Weisz, 2018). Her model allows her to have a high impact because she reaches many people, produces results using minimal money and time from patients, and helps an otherwise neglected population. In countries or regions where there are few or no formally trained mental health professionals, best practices to treat more people include training non-specialists to provide psychosocial services for select, less acute MNS disorders (Patel et al., 2016; Snowden et al., 2019).

3.3.2 Daring unusual prescriptions. A growing body of research is investigating the efficacy of prescribing open-label, non-deceptive placebos to relieve depression (Kelley et al., 2012; Nitzan et al., 2020), emotional distress (Guevarra et al., 2020), fatigue (Hoenemeyer et al., 2018; Zhou et al., 2019), migraines (Kam-Hansen et al., 2014), and pain (Locher et al., 2017; Mundt et al., 2017; Schneider et al., 2020). Doctors and ethicists have long discussed the potential benefits of prescribing placebos (Bok, 1974), but do not do so because it requires deceiving patients (although many doctors prescribe placebos nonetheless; Tilburt et al., 2008). Recent research on open-label, non-deceptive placebos overcomes the issue of deceit, and is motivated by evidence that placebos can be equally as effective at treating low to moderate depression antidepressants (Fournier et al., 2010; Kirsch et al., 2008) and that placebos are much 
cheaper than antidepressants (i.e., they may be more cost-effective). Although the idea of using open-label placebos is often met with surprise and skepticism (Kaptchuk, 2018), counterintuitive ideas like this may be under-examined precisely because people assume they will not work and instinctively reject them (Lane \& Harris, 2014).

Another potential prescription could involve encouraging patients to engage in altruism and prosocial behavior. Across the world, spending money on others (Aknin et al., 2013, 2020) and volunteering (Borgonovi, 2008; Meier \& Stutzer, 2008; Post, 2005; Thoits \& Hewitt, 2001; ) can improve wellbeing. Volunteering and helping are also associated with lower rates of anxiety and depression (Hunter \& Linn, 1981; Musick \& Wilson, 2003; Schwartz et al., 2003), morbidity (Brown et al., 2005) and mortality (Moen et al., 1989; Musick et al., 1999; Oman et al., 1999; ). Even altruism toward non-human animals can provide mutual benefits for both the people and animals involved (for a review, see Dizon et al., 2007). The idea of prescribing altruism comes with caveats--altruistic acts are more likely to have health benefits for givers if they have feelings of autonomy (Weinstein \& Ryan, 2010) and social connection (Aknin et al., 2013), and are not overtaxing (Schwartz et al., 2003); likewise, prescribing altruistic acts will have greater impact on society if people are given information on how to donate time or money to effective organizations.

3.3.3 Considerations for which mental health issues to focus on. Clinicians interested in maximizing their impact may consider developing treatments to address MNS disorders that are the most cost-effective to treat and that rank highly in ITN assessments. The Global Burden of Disease Study (The Lancet, 2020) and the Disease Control Priorities Study (Patel et al., 2016) have estimated the mental health disorders that account for the most DALYs (depression and anxiety, which respectively account for an estimated $1.8 \%$ and $1.1 \%$ of DALYs) and the most 
cost-effective MNS disorders to treat in DALYs saved per dollar (schizophrenia, via community-based treatment with antipsychotic medication and psychosocial treatment). They also review best practices for maximizing impact at different levels of intervention (e.g., community level vs. health-care platform level) and for different MNS disorders. The Global Burden of Disease data can also be filtered by region to provide individual clinicians with personally relevant data to inform which mental health issues to focus on.

Additionally, clinicians may consider which issues are most relatively neglected or tractable. To our knowledge, no work has formally estimated the neglectedness and tractability of specific mental health issues compared to other mental health issues and/or compared to other health issues more generally. However, a report by Walker and colleagues (2021; sections 4.2 and 5) makes a strong case for the overall neglectedness of mental health, referring to data suggesting shocking levels of undertreatment for depression (in a survey based on representative samples from 21 countries, only 1 in 27 people receive minimally adequate treatment, Thornicroft et al., 2017); and promising levels of tractability (Huhn et al., 2014). To illustrate likely differences in importance and neglectedness, Figure 1 shows the DALYs attributed to different mental health issues in the Global Burden of Disease Study 2019 (2020), as well as the number of yearly papers containing those disorders in the title published in a PubMed search from 2016 to 2019 (see SOM 5 for details). For example, the words related to autism appeared in the title of about 3500 papers per year, which is about the same number as for a variety of words associated with self-harm, despite the fact that the latter is attributed eight times as many DALYs than the former. 


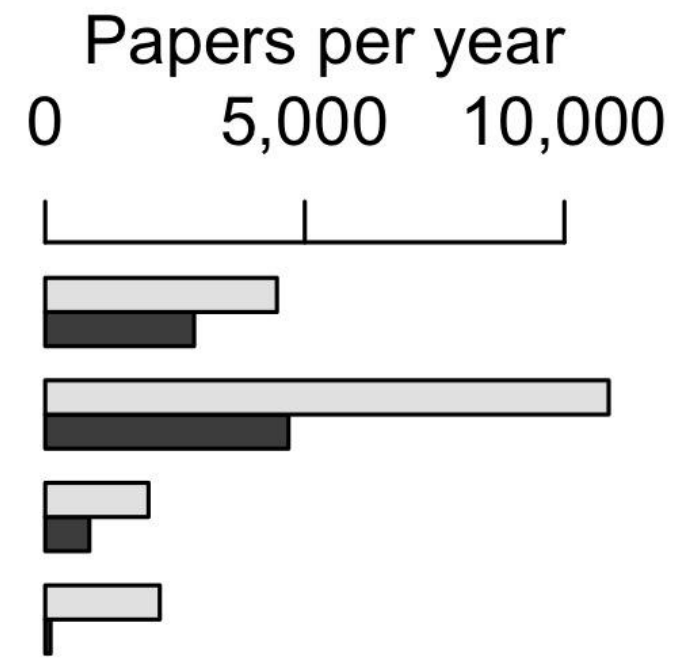

Autism spectrum disorders

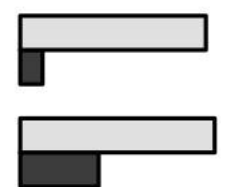

Schizophrenia

Eating disorders

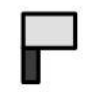

Substance disorders

Self-harm behaviors

$\square$ Papers
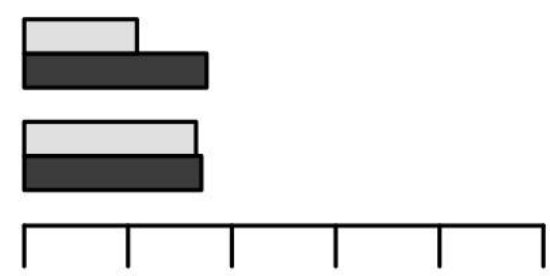

$0 \quad 40 \quad 80$

DALYs (millions)

Figure 1. Selection of mental health issues' importance, measured in Disability Adjusted Life Years (DALYs, which takes into account jointly the problem's prevalence and its severity), together with the number of papers likely bearing on that issue. The scale was chosen purely for visual purposes. ADHD stands for Attention Deficit and Hyperactivity Disorder.

3.3.4 Considerations for which populations to focus on. Clinicians with the opportunity to work with people from regions in which mental health issues are more prevalent 
and/or more neglected will have a greater impact than those working in countries where these issues are less common or already better addressed. On a global scale, research suggests that mental health is very neglected in low and middle income countries, which spend less than \$2 per year per person on treatment and prevention of mental disorders, compared to over $\$ 50$ in high income countries (Snowden et al., 2019). Additionally, prevalence also varies across countries; for instance, an OECD report estimated the prevalence of anxiety and depression in 2020 at 50\% and 37\% respectively in Mexico, versus 20\% and 10\% in Canada (OECD, 2021).

Even in so-called rich countries, there are populations who are underserved, because of geographic and/or financial limitations: Over $70 \%$ of urban US counties have at least one mental health facility accessible to the youth, compared to less than $50 \%$ of rural counties (Cummings et al., 2013). According to an analysis of 2010 National Health Interview Survey data (Roll et al., 2013), unmet mental health needs were greater for children (aged 2-17 years), women, low-income people, and uninsured people--for example, uninsured people's unmet needs were 5 times higher than those of insured people. Although problems at this scale certainly require systemic solutions, individual clinicians can increase access by using telehealth, taking public insurance, and offering sliding scale payments, thereby increasing their impact by helping people who may not otherwise receive help. Given constrained budgets, systemic solutions may prioritize programs with greatest return to investment, which based on current data may be early childhood interventions (saliently cognitive stimulation programs, Busso et al., 2017, ch. 1 and $6)$.

\subsection{Research}

3.3.1 Considerations for impactful research topics. Researchers can attempt to evaluate the potential impact of research projects using the ITN framework. At this point, it is 
crucial to reflect on the fact that here we define altruistic importance (and not other potential aspects of research that are certainly worthy of considerations, such as innovativeness). Within the altruistic ITN framework we are employing, an "important" project may involve an intervention that directly affects many people (e.g., a state-wide RCT), but projects can also be important because of their potential indirect effects; for instance, if they bear on a topic that affects (or will affect) many people (e.g., climate change), or if they have transferable implications for many other research projects (e.g., developing a new and flexible measurement tool; a theory with wide applicability).

Take the example of research showing that rates of organ donation are much higher when the default is opt-out (vs. opt-in) (Johnson \& Goldstein, 2003). This work demonstrated large effects for a high-impact outcome (organ donation saves lives), the topic and effects are relevant to many people (it was examined in governments across the world), and the findings were transferable to many other topics (i.e., defaults have been shown to affect other important outcomes, such as financial savings and healthy eating). To take another example, consider methodological advancements around experience sampling methods (e.g., Csikszentmihalyi \& Larson, 1987; Stachl et al., 2020) that combine the advantages of highly controlled sampling methods with observations in the field. These improved the quality of testing and generating theories (e.g., Hofmann et al., 2014; Sherman et al., 2015) while also enhancing applied insights, such as into psychopathological conditions in daily life (e.g., Kuppens et al., 2010; Trull \& Ebner-Priemer, 2009). Crucially, projects may be arguably important even if they do not have direct impact today, such as discussing the moral relevance of artificial agents: There are no artificial agents today who are person-like, but their potential existence invites a host of questions about our perception of them and their rights (e.g., Festerling \& Siraj, 2020). 
Along with importance, researchers should account for a problem's theoretical tractability (e.g., a single-shot intervention designed to increase general intelligence by two standard deviations) and practical tractability (e.g., interventions that cannot scale due to insufficient resources or a lack of public acceptance, such as genetic editing to avoid mental health disorders; Walker et al., 2021). Sometimes it is useful to decompose tractability further: Stern and colleagues (e.g., Nielsen et al., 2021; Stern, 2011) estimate the effective impact of environmental behavior interventions by multiplying the intervention's "technical potential" (the reduction in greenhouse gas emission from a behavior's universal adoption) by its "behavioral plasticity" (the degree to which the behavior can be changed) by the "initiative feasibility" (the degree to which an intervention can actually be implemented). In the search for levers that are both high in technical potential and plasticity, psychological theories play a crucial role (Lange, et al., 2021).

Regarding neglectedness, researchers may consider that one's marginal impact on a given problem is likely to be lower if it is oversaturated with people already addressing it. A topic could be neglected in different ways, ranging from theoretical to empirical approaches. For example, global priorities researchers suggest that human extinction risks are relatively neglected (United Nations Secretary-General, 2021), and it is likely that studying the psychology of how humans respond to these risks is also understudied (we expand on this in the below section on "Researching EA-Inspired Topics").

Applying ITN to a research topic decision process can be daunting. Robust research quantifying the potential importance, neglectedness, and tractability of psychological research topics could be very impactful itself, as it would help people identify and prioritize outstanding research opportunities to contribute to the common good. To this end, we need to create metrics allowing us to get a more objective assessment of how a project may fare by the ITN criteria. 
One related effort is the research priorities project being led by Lieder and colleagues (in progress), aimed at identifying important research questions on how to ensure the long term flourishing of humanity (Lieder, 2021). The research priorities project first solicited ideas from researchers. Next, jury members evaluated whether these ideas should be considered among the research priorities shortlist (which currently includes 36 ideas). Shortlisted ideas are currently being elaborated on in a rubric with written, open-ended intuitions about how they fare on the ITN criteria, relevant prior literature, success criteria, and feedback from project contributors. Once the shortlisted ideas have been fleshed out in the rubric, impact assessors will evaluate various ideas in a survey with quantitative estimates of tractability (using a scale response about the likelihood of solving the issue), cost (by estimating the number of person-years of full-time work to answer the research question and additional monetary costs), solvability (by estimating “in how many out of 10,000 possible worlds" the proposed goal could be achieved), neglectedness (using a scale about beliefs about whether the topic receives sufficient attention and money), benefits (using a scale rating how beneficial the successful completion of this research be for the long-term flourishing of humanity, with examples of the concrete benefits).

3.3.2 Researching EA-inspired topics. A potential shortcut to conducting impactful research may be to focus on how psychology can address topics prioritized by effective altruists. Mental health is one such topic, as summarized in Section 3.2. Other prominent cause areas in EA, based on research done at 80,000 hours using the ITN framework, include ineffective charitable giving, global catastrophic and existential risks, institutional decision-making, and animal welfare (80,000 Hours, 2021). Below, we summarize research done at the intersection of psychology and each of these topics; we provide a more comprehensive list of psychological 
research with strong EA links in the SOM 3. For readers who are interested in conducting similar research, we present other candidate ideas in SOM $4 .^{1}$

Ineffective altruism. Caviola and colleagues (2021) recently reviewed the motivation to research ineffective giving, its psychological underpinnings, and solutions to this problem. Regarding its justification as a problem worth addressing, they note:

Most research on charitable giving focuses on the amounts that donors give. However, if the societal goal of charitable giving is to improve human (or animal) well-being, it is probably more important to focus on the effectiveness of giving. This is because the variation in charity effectiveness is much larger than the variation in donation amounts that a donor is likely to consider: you can double your impact by doubling the amount that you give to typical charities, but you can multiply your impact by a factor of ten, 100 , or even 1000 by choosing to support more effective charities.

Accordingly, several scholars have studied the psychological reasons why people are often ineffective in their altruism (e.g., Baron \& Szymanska, 2011; Caviola et al., 2020; Lewis \& Small, 2019; Burum et al., 2020; Caviola et al., 2021). Caviola and colleagues classify psychological impediments to effective giving into motivational and epistemic obstacles to effective altruism.

They include among motivational obstacles the subjectivity of giving (Berman et al., 2018); narrow affective motivations for giving (e.g., a reliance on personal connection, Berman et al., 2018; favoring proximate beneficiaries, Jones \& Rachlin, 2006); aversion to prioritizing (Paolacci \& Yalcin, 2020); and character and reputational benefits (Montealegre et al., 2020). One specific example is psychic numbing, i.e., people's tendency to feel less compassion and donate less money as the number of people in need increases (Slovic, 2007).

\footnotetext{
${ }^{1}$ Potential funding, including for impactful psychology research, is listed in Aird (2021). Note that funding for EA-aligned projects was growing faster than applications for that funding between 2019 and 2021 (Todd, 2021), meaning that, at the time of writing, it is timely to apply.
} 
Epistemic obstacles that they note include quantifiability skepticism, innumeracy, underestimation of effectiveness variance, and ignorance about the most effective charities (Caviola et al., 2020). They also review research on strategies to reduce ineffective altruism, such as providing information (Caviola et al., 2020), choice architecture (including defaults, incentives, unit asking, and splitting; e.g., Everett et al., 2015; Hsee et al., 2013), philosophical reasoning (Huang et al., 2019), and norm changes (Sparkman \& Walton, 2017). One such example is the overhead myth, i.e., people's tendency to avoid charities with high administrative costs despite these costs being unrelated to cost-effectiveness (Caviola et al., 2014).

In a more recent development, Lewis and colleagues (2021) aim to address systematic ineffective altruism by creating a "EA Market Testing Team"--an informal group of professional marketers, business academics, economists, and representatives of EA organizations--with the aim of identifying "the most effective, scalable strategies" for increasing effective giving (among other outcomes). They plan on using testing multiple levers (e.g., support from respected public figures; emotional imagery) and multiple methods of testing (e.g., advertising campaigns on heavily trafficked websites such as YouTube and Facebook; focus groups).

Global Catastrophic and Existential risk. Global catastrophic risks pose a threat to human well-being on a global scale--including threats that could result human extinction (i.e., existential risks ${ }^{2}$ )--and some are relatively neglected (although there is variation in how tractable they are; Ord, 2020, ch. 6). Consistent with the long history of the psychology of risk, psychologists can study how people think, feel, and behave with regards to global catastrophic risks. One well-studied example is research on psychology and climate change, where scholars have examined perceptions of climate change (Hornsey et al., 2016); obstacles to belief in

\footnotetext{
${ }^{2}$ Existential risk refers to a broader class of undesirable futures such as a global totalitarian regime or human society being irreparably destroyed.
} 
climate change (e.g., psychological distance, Spence et al., 2012); how climate change affects psychological outcomes (e.g., mental health outcomes, Berry et al., 2010); and efforts to change climate change behaviors (Lange \& Brick, 2021).

Other global catastrophic risks have received less attention among psychologists, including artificial intelligence, nuclear and biological warfare, and pandemics (although the COVID-19 pandemic sparked increased research into how people think about naturally occurring pandemics, Dezecache et al., 2020). Some of these problems are less connected to the behavior of the general population, as opposed to government actors (nuclear and biological warfare) or otherwise specialized actors (e.g., artificial intelligence), and may therefore be especially relevant to psychologists who study leaders and politicians, but less relevant to those who focus on lay people. At the same time, it is possible that understanding how members of the general population think about global catastrophic risks will be important to humanity's long-term prospects of combating them, even if there are no behavioral interventions that directly address the risk.

One global catastrophic risk that the EA community discusses concerns artificial intelligence: According to Ord (2020), artificial intelligence has tremendous potential to either improve human welfare or cause human extinction (a 10\% chance over the next 100 years; Ord, 2020, ch. 6). Psychology and cognitive science are relevant to the future of artificial intelligence, such as helping define what "artificial general intelligence" means and how to measure it (Wang, 2019). In addition, one of the proposed solutions to this risk involves aligning artificial intelligence with our values, which requires research into human values and which values and value alignments best promote flourishing societies. 
Broader research into how people think, feel, and behave with respect to global catastrophic risks in general may also prove useful. Two such examples include a chapter summarizing how many well-established cognitive biases may explain irrational judgment and behavior relevant to global catastrophic risks (e.g., availability heuristic; Yudkowsky, 2008) and a paper examining how people reason about threats to human extinction (Schubert et al., 2019). Schubert and colleagues (2019) focused on existential risk in particular because it poses an outsized threat to humanity, as it would result in the loss of all living and future humans, making it uniquely bad and much worse than a global catastrophic event killing the vast majority of humans; this is why some effective altruists focus on existential risks as a cause area. And yet, their results indicated that participants did not evaluate extinction risks to be uniquely bad relative to catastrophic non-extinction risks, which the authors interpret as participants neglecting the long-term consequences of human extinction. These results offer a potential clue as to why global priorities researchers have found existential risks to be relatively neglected.

Institutional decision-making. Psychology research has long illustrated that people often are suboptimal decision-makers (Ariely \& Jones, 2008; Kahneman \& Tversky, 1979). When in strategic institutional roles, individuals and groups have unprecedented abilities to make decisions that could improve or harm billions of people. Thus, improving institutional decision-making is a natural issue where psychological research can have a large impact.

Psychologists and others have explored many interventions to improve individual and group decision-making, which can be grouped into technical interventions (e.g., choice architecture, Thaler et al., 2013; decision aids, O’Connor et al., 1999; prediction markets, Wolfers \& Zitzewitz, 2004) and sociopolitical interventions (e.g., accountability systems, Tetlock, 1999; incentive design, Seabright, 1993). In addition, psychologists have examined the 
factors that produce accurate forecasts of the future, which is important for optimal decision-making. Notable existing work on this topic includes research on forecasting (Mellers et al., 2014; Tetlock \& Gardner, 2015), which has shown that individual differences (e.g., active open-minded thinking; Stanovich \& West, 1997) and strategies (e.g., probability training, team collaboration, non-judgmental brainstorming; Mellers et al., 2014) can improve people's judgment and decisions.

One potential strategy for improving group judgment and decision-making is group deliberation. Research on groupthink (Janis, 2008) and group polarization (Myers \& Lamm, 1976) has highlighted the potential dangers of group decision-making, but when done well, group deliberation increases in information sharing (Mellers et al., 2014) and fact-based reasoning (Fishkin \& Luskin, 2005), and can also lead to desirable outcomes such as increased concern for outgroups (Grönlund et al., 2017) and future generations (Hara et al., 2019). Psychological research has also identified features that can improve deliberation quality (e.g., accountability, Lerner \& Tetlock, 1999; diverse groups, Mutz, 2002) or degrade it (e.g., group members with intense preferences, members with excessive power over others; Shapiro, 2017).

Going forward, high impact psychological research on this topic may include how to develop the dispositions, skills, and strategies that characterize expert decision-makers; how to structure decision-making environments in ways that promote optimal decision-making; conducting research on decision-making among those with influence in key institutions (e.g., government and military officials); shifting valued outcomes to be more altruistic; and ways of incorporating findings from all such research in institutions.

Animal welfare. Animal consciousness is widely acknowledged among philosophers and psychologists (Francken et al., 2021), which includes the capacity for suffering (Singer, 
1979/2011; Wild, 2019). Given the scale (and relative neglectedness) of animal suffering, it is a common cause area in EA. It has been estimated that more than 46 billion sea animals and 9 billion land animals are killed annually for food only in the US, with most land animals being raised and slaughtered in industrial production facilities (Broad, 2018). Such facilities inflict a large suffering burden on animals (Weathers et al., 2020), they are accordingly judged as morally impermissible by large parts of professional ethicists (Schönegger \& Wagner, 2019) and the general public (Federal Ministry of Food and Agriculture, 2016; Hartmann \& Siegrist, 2020). Addressing animal welfare can also have large synergy effects: plant-based diets for instance, have a lower carbon footprint (Willett et al., 2019; Wynes \& Nicholas, 2017), reduce dietary food risks (Afshin et al., 2019), and inflict less animal suffering (Kolbe, 2018).

Psychological research is already contributing to this topic by capturing moral judgments and behaviors around animals and animal welfare (Caviola et al., 2019; Feinberg et al., 2019; Loughnan et al., 2010; Wilks et al., 2021); human-animal relationships (Amiot \& Bastian, 2015); behavioral science interventions aimed at reducing meat consumption (Carfora et al., 2017; Jalil et al., 2020; Sparkman \& Walton, 2017; Sparkman et al., 2020; Schwietzgebel et al., 2020); the drivers of other behaviors that affect animal welfare (e.g., animal rights activism, Feinberg et al., 2020); and insights into certain animals' capacity for thinking, feeling, and suffering (e.g., Marino, 2017). There is additional space for EA-inspired basic research relevant to this topic. Most saliently, the species that have attracted attention of animal sentience researchers are not necessarily those that are farmed at scale (e.g., chickens), meaning we have insufficient knowledge on the animals whose welfare we most affect. Additionally, sometimes decisions are made to replace one animal for another (e.g., in laboratory tests), again without knowledge of their relative capacities (see Fischer et al., 2021, for further arguments and a proposal for 
interspecies welfare comparison). Some of these issues will require strong interdisciplinary collaborations, which may be particularly attractive to certain psychologists (an encouraging example in Rethink Priorities, 2021).

\section{Recommendations for psychology as a field}

Psychology, as a field, can do the most good by making institutional-level changes, in addition to the individual level changes recommended in Section 3. We review these potential changes here, with subsections dedicated to the different functions that institutions serve within the field.

\subsection{Evaluation}

One important practice that often occurs at the institutional level is evaluation. Psychology departments, clinics, and other places of employment for psychologists often evaluate potential candidates; granting agencies evaluate grant proposals for research and application; journals evaluate which research should be published; and many institutions give out awards that recognize individuals. Collectively, these institutions have a profound influence on how psychology is done by shaping the norms and incentives for individuals.

For example, job openings could encourage candidates to highlight the social impact of their research in their job materials (e.g., in their research and teaching statements). Similarly, research sponsors and regulators considering proposals (for research or application work) could require a statement of impact (similar to the NSF's broader impact criteria) that considers importance, tractability, and neglectedness, as well as other metrics such as cost-effectiveness for issues for which intervention evaluation is currently possible. 
Additionally, badges and awards could be created in other institutional contexts, in order to recognize individuals or their output based on impact-relevant features (e.g., for a research project, the use of estimates of cost-effectiveness, evaluations based on the ITN framework, and the consideration and potential measurement of positive and negative side effects).

\subsection{Increasing connectedness and visibility}

Another step institutions could take is in creating spaces to showcase and promote psychology work that is relevant to effective altruism or incorporates approaches consistent with effective altruism. There are many examples of what this could look like. For instance, these efforts could be more psychology-focused, such as new APA divisions that address certain causes or new satellite events at psychology conventions that focus on a specific cause thought to be impactful or effective altruism more broadly. As for research, these efforts could also be more interdisciplinary--new journals, conferences, and organizations within universities could intentionally bring together scholars from different disciplines working on the same high-impact cause areas. Efforts such as these would incentivize a positive-impact frame of mind, connect individuals motivated by these issues, and provide them with a space to nourish and highlight their efforts. A recent example of a relevant conference was the Life Improvement Science conference--an interdisciplinary conference focused on understanding "the psychological and socio-cultural mechanisms of well-doing in tandem with developing tools and interventions that help people grow, live a meaningful life, and make valuable contributions...[with] the ultimate goal is to promote the long-term well-doing of humanity" (Lieder, 2021).

\section{Conclusion}


Many psychologists are motivated to use their careers to have a positive impact on other people. History has proven that this is often more difficult than it seems. The effective altruism movement provides novel concepts and tools that can allow the field of psychology to maximize its positive impact on the world. In this article, we explored this idea by highlighting how psychologists in various roles (teachers, clinicians, and researchers) and psychology institutions can use effective altruism to do the most good in the world.

We see this article as a call to action and as a collection of ideas to investigate and ensure that our actions are as impactful as possible. To be clear, there is no single or sure way to do the most good as a psychologist--even the authors of this article have different ideas about the best ways for psychologists to maximize their impact. Instead, we hope that this article starts conversations, inspires new ideas, and leads people to take lasting and meaningful actions to do the most good. 


\section{Supplementary online materials}

Supplementary Online Materials 1: Position statements by two of the authors, illustrating diversity in thinking within the EA community.

Supplementary Online Materials 2: Recommendations about other roles psychologists may have. Supplementary Online Materials 3: Suggested reading on research in psychology inspired by, or with strong connections to, Effective Altruism.

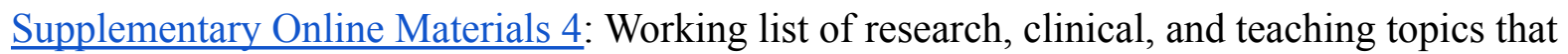
may be particularly impactful.

Supplementary Online Materials 5: Methodology to create Figure 1. 


\section{References}

80,000 Hours. (2021, October 20). Our current list of the most important world problems. 80,000 Hours. Retrieved November 2, 2021, from https://80000hours.org/problem-profiles.

Afshin, A., Sur, P. J., Fay, K. A., Cornaby, L., Ferrara, G., Salama, J. S., Mullany, E. C., Abate, K. H., Abbafati, C., Abebe, Z., Afarideh, M., Aggarwal, A., Agrawal, S., Akinyemiju, T., Alahdab, F., Bacha, U., Bachman, V. F., Badali, H., Badawi, A., ... Murray, C. J. L. (2019). Health effects of dietary risks in 195 countries, 1990-2017: A systematic analysis for the Global Burden of Disease Study 2017. The Lancet, 393(10184), 1958-1972. https://doi.org/10.1016/S0140-6736(19)30041-8

Aird, M. (2021). List of EA funding opportunities. Effective Altruism Forum, https://forum.effectivealtruism.org/posts/DqwxrdyQxcMQ8P2rD/list-of-ea-funding-oppo rtunities, last visited 2021-11-08.

Aknin, L. B., Barrington-Leigh, C. P., Dunn, E. W., Helliwell, J. F., Burns, J., Biswas-Diener, R., Kemeza, I., Nyende, P., Ashton-James, C. E., \& Norton, M. I. (2013). Prosocial spending and well-being: Cross-cultural evidence for a psychological universal. Journal of Personality and Social Psychology, 104(4), 635-652

Aknin, L. B., Dunn, E. W., Proulx, J., Lok, I., \& Norton, M. I. (2020). Does spending money on others promote happiness?: A registered replication report. Journal of Personality and Social Psychology, 119(2), e15.

American Psychiatric Association. (2013). Diagnostic and statistical manual of mental disorders (5th ed.). https://doi.org/10.1176/appi.books.9780890425596

Amiot, C. E., \& Bastian, B. (2015). Toward a psychology of human-animal relations. Psychological Bulletin, 141(1), 6-47. https://doi.org/10.1037/a0038147 
Ariely, D., \& Jones, S. (2008). Predictably irrational. New York, NY: Harper Audio.

Arokoyo, B. E., Benavides-Varela, S., Boll-Avetisyan, N., Aravena Bravo, P., ... Woon, F. T. (2021). First /L+/ International summer/winter school on language acquisition. https://www.dpss.unipd.it/summer-school-2021/home, last visited 2021-10-21.

Baron, J., \& Szymanska, E. (2011). Heuristics and biases in charity. In D. M. Oppenheimer \& C. Y. Olivola (Eds.), The science of giving (pp. 215-235). London: Psychology Press. https://doi.org/10.4324/9780203865972

Barlow, D. H. (2010). Negative effects from psychological treatments: a perspective. American psychologist, 65(1), 13.

Barry, M. M., Clarke, A. M., Jenkins, R., \& Patel, V. (2013). A systematic review of the effectiveness of mental health promotion interventions for young people in low and middle income countries. BMC public health, 13(1), 1-19.

Berman, J. Z., Barasch, A., Levine, E. E., \& Small, D. A. (2018). Impediments to effective altruism: The role of subjective preferences in charitable giving. Psychological science, 29(5), 834-844.

Bok, S. (1974). The ethics of giving placebos. Scientific American, 231(5), 17-23.

Berry, H. L., Bowen, K., \& Kjellstrom, T. (2010). Climate change and mental health: a causal pathways framework. International journal of public health, 55(2), 123-132.

Borgonovi, F. (2008). Doing well by doing good. The relationship between formal volunteering and self-reported health and happiness. Social science \& medicine, 66(11), 2321-2334.

Brown, W. M., Consedine, N. S., \& Magai, C. (2005). Altruism relates to health in an ethnically diverse sample of older adults. The Journals of Gerontology Series B: Psychological Sciences and Social Sciences, 60(3), P143-P152. 
Burum, B., Nowak, M. A., \& Hoffman, M. (2020). An evolutionary explanation for ineffective altruism. Nature Human Behaviour, 4(12), 1245-1257. https://doi.org/10.1038/s41562-020-00950-4

Busso, M., Cristia, J., Hincapié, D., Messina, J., \& Ripani, L. (Eds.). (2017). Learning better: Public policy for skills development. Inter-American Development Bank.

Broad, G. M. (2018). Effective animal advocacy: Effective altruism, the social economy, and the animal protection movement. Agriculture and Human Values, 35(4), 777-789. https://doi.org/10.1007/s10460-018-9873-5

Carfora, V., Caso, D., \& Conner, M. (2017). Randomised controlled trial of a text messaging intervention for reducing processed meat consumption: The mediating roles of anticipated regret and intention. Appetite, 117, 152-160. https://doi.org/10.1016/j.appet.2017.06.025

Castelnuovo, G., Pietrabissa, G., Cattivelli, R., Manzoni, G. M., \& Molinari, E. (2016). Not only clinical efficacy in psychological treatments: clinical psychology must promote cost-benefit, cost-effectiveness, and cost-utility analysis. Frontiers in psychology, 7, 563. https://doi.org/10.3389/fpsyg.2016.00563

Caviola, L., Faulmüller, N., Everett, J. A., Savulescu, J., \& Kahane, G. (2014). The evaluability bias in charitable giving: Saving administration costs or saving lives? Judgment and decision making, 9(4), 303.

Caviola, L., Everett, J. A. C., \& Faber, N. S. (2019). The moral standing of animals: Towards a psychology of speciesism. Journal of Personality and Social Psychology, 116(6), 1011-1029. https://doi.org/10.1037/pspp0000182 
Caviola, L., Schubert, S., \& Greene, J. D. (2021). The psychology of (in)effective altruism. Trends in Cognitive Sciences, 25(7), 596-607.

Caviola, L., Schubert, S., \& Nemirow, J. (2020). The many obstacles to effective giving. Judgment and Decision Making, 15(2), 159-172

Cummings, J. R., Wen, H., \& Druss, B. G. (2013). Improving Access to Mental Health Services for Youth in the United States. JAMA, 309(6), 553-554. https://doi.org/10.1001/jama.2013.437

Csikszentmihalyi, M., \& Larson, R. (1987). Validity and reliability of the experience sampling method. Journal of Nervous and Mental Disease, 175(9), 529-536.

Dezecache, G., Frith, C. D., \& Deroy, O. (2020). Pandemics and the great evolutionary mismatch. Current Biology, 30(10), R417-R419.

Dizon, M., Bulter, L. D., \& Koopman, C. (2007). Befriending man's best friends: Does altruism toward animals promote psychological and physical health? In S. G. Post (Ed.), Altruism and health: Perspectives from empirical research (pp. 278-289). Retrieved from http://www.oxfordscholarship.com/view/10.1093/acprof:oso/9780195182910.001.0001/a cprof-9780195182910

Durlak, J. A., Weissberg, R. P., Dymnicki, A. B., Taylor, R. D., \& Schellinger, K. B. (2011). The impact of enhancing students' social and emotional learning: A meta-analysis of school-based universal interventions. Child development, 82(1), 405-432.

Ehring, T., \& Watkins, E. R. (2008). Repetitive negative thinking as a transdiagnostic process. International journal of cognitive therapy, 1(3), 192-205. 
Everett, J. A., Caviola, L., Kahane, G., Savulescu, J., \& Faber, N. S. (2015). Doing good by doing nothing? The role of social norms in explaining default effects in altruistic contexts. European Journal of Social Psychology, 45(2), 230-241.

Farber, B. A., Manevich, I., Metzger, J., \& Saypol, E. (2005). Choosing psychotherapy as a career: Why did we cross that road? Journal of Clinical Psychology, 61(8), 1009-1031. https://doi.org/10.1002/jclp.20174

Federal Ministry of Food and Agriculture. (2016). Deutschland, wie es isst. Der BMEL-Ernährungsreport. Bonifatius.

Feinberg, M., Kovacheff, C., Teper, R., \& Inbar, Y. (2019). Understanding the Process of Moralization: How Eating Meat Becomes a Moral Issue. Journal of Personality \& Social Psychology, 117(1), 50-72.

Feinberg, M., Willer, R., \& Kovacheff, C. (2020). The activist's dilemma: Extreme protest actions reduce popular support for social movements. Journal of Personality and Social Psychology. https://doi.org/10.1037/pspi0000230

Festerling, J., \& Siraj, I. (2020). Alexa, what are you? Exploring primary school children's ontological perceptions of digital voice assistants in open interactions. Human Development, 64(1), 26-43.

Fischer, R., Caeiro, C., Schnell, A., \& Schukraft, J. (2021). Comparing Animals’ Welfare: A Methodology for Improving Interspecies Welfare Comparisons via Comparative Capacity for Welfare. Paper under review.

Fishkin, J. S., \& Luskin, R. C. (2005). Experimenting with a democratic ideal: Deliberative polling and public opinion. Acta politica, 40(3), 284-298. 
Fournier, J. C., DeRubeis, R. J., Hollon, S. D., Dimidjian, S., Amsterdam, J. D., Shelton, R. C., \& Fawcett, J. (2010). Antidepressant drug effects and depression severity: a patient-level meta-analysis. Jama, 303(1), 47-53.

Francken, J., Beerendonk, L., Molenaar, D., Fahrenfort, J. J., Kiverstein, J., Seth, A., \& van Gaal, S. (2021). An academic survey on theoretical foundations, common assumptions and the current state of the field of consciousness science [Preprint]. PsyArXiv. https://doi.org/10.31234/osf.io/8mbsk

Frank, R. H., Gilovich, T. D., \& Regan, D. T. (1996). Do economists make bad citizens?. Journal of Economic Perspectives, 10(1), 187-192.

Global Burden of Disease Study 2019 (GBD 2019) Results. Seattle, United States: Institute for Health Metrics and Evaluation (IHME), 2020. Available from http://ghdx.healthdata.org/gbd-results-tool.

Grönlund, K., Herne, K., \& Setälä, M. (2017). Empathy in a citizen deliberation experiment. Scandinavian Political Studies, 40(4), 457-480.

Guevarra, D. A., Moser, J. S., Wager, T. D., \& Kross, E. (2020). Placebos without deception reduce self-report and neural measures of emotional distress. Nature communications, $11(1), 1-8$

Greaves, H., \& MacAskill, W. (2019). The case for strong longtermism (No. 7-2019). Global Priorities Institute Working Paper Series. GPI Working Paper.

Greaves, H., \& Pummer, T. (Eds.). (2019). Effective altruism: Philosophical issues. Oxford University Press.

Hara, K., Yoshioka, R., Kuroda, M., Kurimoto, S., \& Saijo, T. (2019). Reconciling intergenerational conflicts with imaginary future generations: Evidence from a 
participatory deliberation practice in a municipality in Japan. Sustainability Science, 14(6), 1605-1619.

Hartmann, C., \& Siegrist, M. (2020). Our daily meat: Justification, moral evaluation and willingness to substitute. Food Quality and Preference, 80, 103-799. https://doi.org/10.1016/j.foodqual.2019.103799

Hilty, D. M., Ferrer, D. C., Parish, M. B., Johnston, B., Callahan, E. J., \& Yellowlees, P. M. (2013). The effectiveness of telemental health: a 2013 review. Telemedicine and e-Health, 19(6), 444-454.

Hoenemeyer, T. W., Kaptchuk, T. J., Mehta, T. S., \& Fontaine, K. R. (2018). Open-label placebo treatment for cancer-related fatigue: a randomized-controlled clinical trial. Scientific reports, $8(1), 1-8$.

Hofmann, W., Wisneski, D. C., Brandt, M. J., \& Skitka, L. J. (2014). Morality in everyday life. Science, 345(6202), 1340-1343. https://doi.org/10.1126/science.1251560

Hornsey, M. J., Harris, E. A., Bain, P. G., \& Fielding, K. S. (2016). Meta-analyses of the determinants and outcomes of belief in climate change. Nature climate change, 6(6), $622-626$.

Huang, K., Greene, J. D., \& Bazerman, M. (2019). Veil-of-ignorance reasoning favors the greater good. Proceedings of the national academy of sciences, 116(48), 23989-23995.

Hsee, C. K., Zhang, J., Lu, Z. Y., \& Xu, F. (2013). Unit asking: A method to boost donations and beyond. Psychological science, 24(9), 1801-1808.

Huhn, M., Tardy, M., Spineli, L. M., Kissling, W., Förstl, H., Pitschel-Walz, G., Leucht, C., Samara, M., Dold, M., Davis, J. M., \& Leucht, S. (2014). Efficacy of pharmacotherapy 
and psychotherapy for adult psychiatric disorders: A systematic overview of meta-analyses. JAMA Psychiatry, 71(6), 706-715.

Hunter, K. I., \& Linn, M. W. (1981). Psychosocial differences between elderly volunteers and non-volunteers. The International Journal of Aging and Human Development, 12(3), 205-213.

Huynh, L., \& Rhodes, P. (2011). Why Do People Choose to Become Psychologists? A Narrative Inquiry. Psychology Teaching Review, 17(2), 64-70.

Jalil, A. J., Tasoff, J., \& Bustamante, A. V. (2020). Eating to save the planet: Evidence from a randomized controlled trial using individual-level food purchase data. Food Policy, 95, 101950.

Janis, I. L. (2008). Groupthink. IEEE Engineering Management Review, 36(1), 36.

Johnson, E. J., \& Goldstein, D. (2003). Do defaults save lives?. https://www.science.org/doi/abs/10.1126/science.1091721

Jones, B., \& Rachlin, H. (2006). Social discounting. Psychological science, 17(4), 283-286. https://journals.sagepub.com/doi/abs/10.1111/j.1467-9280.2006.01699.x

Kahneman, D., \& Tversky, A. (1979). Prospect theory: An analysis of decision under risk. Econometrica, 47(2), 263-292.

Kam-Hansen, S., Jakubowski, M., Kelley, J. M., Kirsch, I., Hoaglin, D. C., Kaptchuk, T. J., \& Burstein, R. (2014). Altered placebo and drug labeling changes the outcome of episodic migraine attacks. Science translational medicine, 6(218), 218ra5-218ra5.

Kaptchuk, T. J. (2018). Open-label placebo: reflections on a research agenda. Perspectives in biology and medicine, 61(3), 311-334. 
Kelley, J. M., Kaptchuk, T. J., Cusin, C., Lipkin, S., \& Fava, M. (2012). Open-label placebo for major depressive disorder: a pilot randomized controlled trial. Psychotherapy and psychosomatics, 81(5).

Kirsch, I., Deacon, B. J., Huedo-Medina, T. B., Scoboria, A., Moore, T. J., \& Johnson, B. T. (2008). Initial Severity and Antidepressant Benefits: A Meta-Analysis of Data Submitted to the Food and Drug Administration. PLOS Medicine, 5(2), e45. https://doi.org/10.1371/journal.pmed.0050045

Kokotajlo, D., \& Oprea, A. (2020). Counterproductive Altruism: The Other Heavy Tail. Philosophical Perspectives, 34(1), 134-163. https://doi.org/10.1111/phpe.12133

Kolbe, K. (2018). Why Milk Consumption is the Bigger Problem: Ethical Implications and Deaths per Calorie Created of Milk Compared to Meat Production. Journal of Agricultural and Environmental Ethics, 31(4), 467-481.

\section{https://doi.org/10.1007/s10806-018-9740-9}

Kuppens, P., Allen, N. B., \& Sheeber, L. B. (2010). Emotional Inertia and Psychological Maladjustment. Psychological Science, 21(7), 984-991. https://doi.org/10.1177/0956797610372634

The Lancet (2020). Special Issue on the Global Burden of Disease 2019. The Lancet, 396, 10258, 1129-1306. http://www.healthdata.org/gbd

Lane, J. D., \& Harris, P. L. (2014). Confronting, representing, and believing counterintuitive concepts: Navigating the natural and the supernatural. Perspectives on Psychological Science, 9(2), 144-160.

Lange, F., \& Brick, C. (2021). Changing Pro-Environmental Behavior: Evidence from (Un) Successful Intervention Studies. 
Lange, F., Nielsen, K. S., Cologna, V., Brick, C., \& Stern, P. C. (2021). Making theory useful for understanding high-impact behavior. A response to van Valkengoed et al.(2021). Journal of Environmental Psychology, 75, 101611.

Lerner, J. S., \& Tetlock, P. E. (1999). Accounting for the effects of accountability. Psychological bulletin, 125(2), 255.

Lewis, J., Reinstein, D., \& Freeman, L. (2021). EA Market Testing. Effective Altruism Forum, https://forum.effectivealtruism.org/posts/HboobjbDwc5KgpNWi/ea-market-testing, last visited 2021-11-08.

Lewis, J., \& Small, D. (2019, June 4). Ineffective Altruism: Giving Less When Donations Do More Good. Available at SSRN: https://ssrn.com/abstract=3399121 or http://dx.doi.org/10.2139/ssrn.3399121

Lieder, F. (2021, June 9). Life Improvement Science: An Emerging Transdisciplinary Research Area [Conference presentation]. Life Improvement Science Conference, https://www.life-improvement.science/life-improvement-science

Lieder, F., Prentice, M., \& Corwin-Renner, E. (March 2021). Understanding and promoting effective well-doing: open questions and emerging approaches. https://www.researchgate.net/publication/347468246_Understanding_and_promoting_eff ective_well-doing_open_questions_and_emerging_approaches

Locher, C., Nascimento, A. F., Kirsch, I., Kossowsky, J., Meyer, A., \& Gaab, J. (2017). Is the rationale more important than deception? A randomized controlled trial of open-label placebo analgesia. Pain, 158(12), 2320-2328. 
Loughnan, S., Haslam, N., \& Bastian, B. (2010). The role of meat consumption in the denial of moral status and mind to meat animals. Appetite, 55(1), 156-159. https://doi.org/10.1016/j.appet.2010.05.043

MacAskill, W. (2015). Doing good better: How effective altruism can help you make a difference. New York, NY: Avery

MacAskill, W., Bykvist, K., \& Ord, T. (2020). Moral Uncertainty. Oxford: Oxford University Press.

Marino, L. (2017). Thinking chickens: A review of cognition, emotion, and behavior in the domestic chicken. Animal Cognition, 20(2), 127-147. https://doi.org/10.1007/s10071-016-1064-4

McDermut, W., Miller, I. W., \& Brown, R. A. (2001). The Efficacy of Group Psychotherapy for Depression: A Meta-analysis and Review of the Empirical Research. Clinical Psychology: Science and Practice, 8(1), 98-116. https://doi.org/10.1093/clipsy.8.1.98

Meier, S., \& Stutzer, A. (2008). Is volunteering rewarding in itself?. Economica, 75(297), 39-59. https://onlinelibrary.wiley.com/doi/abs/10.1111/j.1468-0335.2007.00597.x

Mellers, B., Ungar, L., Baron, J., Ramos, J., Gurcay, B., Fincher, K., Scott, S. E., Moore, D., Atanasov, P., Swift, S. A., Murray, T., Stone, E., \& Tetlock, P. E. (2014). Psychological strategies for winning a geopolitical forecasting tournament. Psychological Science, 25(5), 1106-1115.

Moen, P., Dempster-McClain, D., \& Williams, R. M. Jr. (1989). Social integration and longevity: An event history analysis of women's roles and resilience. American Sociological Review, 635-647. 
Montealegre, A., Bush, L., Moss, D., Pizarro, D., \& Jimenez-Leal, W. (2020, April 11). Does Maximizing Good Make People Look Bad? https://doi.org/10.31234/osf.io/2zbax

Mundt, J. M., Roditi, D., \& Robinson, M. E. (2017). A comparison of deceptive and non-deceptive placebo analgesia: efficacy and ethical consequences. Annals of Behavioral Medicine, 51(2), 307-315.

Musick, M. A., Herzog, A. R., \& House, J. S. (1999). Volunteering and mortality among older adults: Findings from a national sample. The Journals of Gerontology Series B: Psychological Sciences and Social Sciences, 54(3), S173-S180.

Musick, M. A., \& Wilson, J. (2003). Volunteering and depression: The role of psychological and social resources in different age groups. Social science \& medicine, 56(2), 259-269. https://www.sciencedirect.com/science/article/abs/pii/S0277953602000254

Mutz, D. C. (2002). Cross-cutting social networks: Testing democratic theory in practice. American Political Science Review, 96(1), 111-126.

Myers, D. G., \& Lamm, H. (1976). The group polarization phenomenon. Psychological bulletin, $83(4), 602$.

Nielsen, K. S., Clayton, S., Stern, P. C., Dietz, T., Capstick, S., \& Whitmarsh, L. (2021). How psychology can help limit climate change. American Psychologist, 76(1), 130-144. https://doi.org/10.1037/amp0000624

Nitzan, U., Carmeli, G., Chalamish, Y., Braw, Y., Kirsch, I., Shefet, D., Krieger, I., Mendlovic, S., Bloch, Y., \& Lichtenberg, P. (2020). Open-Label placebo for the treatment of unipolar depression: Results from a randomized controlled trial. Journal of Affective Disorders, $276,707-710$. 
O'Connor, A. M., Rostom, A., Fiset, V., Tetroe, J., Entwistle, V., Llewellyn-Thomas, H., Holmes-Rovner, M., Barry, M., \& Jones, J. (1999). Decision aids for patients facing health treatment or screening decisions: systematic review. Bmj, 319(7212), 731-734.

OECD (2021). Tackling the mental health impact of the COVID-19 crisis: An integrated, whole-of-society response. Last accessed 2021-November 15, https://www.oecd.org/coronavirus/policy-responses/tackling-the-mental-health-impact-of -the-covid-19-crisis-an-integrated-whole-of-society-response-0ccafa0b/.

Oman, D., Thoresen, C. E., \& McMahon, K. (1999). Volunteerism and mortality among the community-dwelling elderly. Journal of Health Psychology, 4(3), 301-316.

Ord, T. (2013). The Moral Imperative Toward Cost-Effectiveness in Global Health. In Effective Altruism (pp. 29-36). Oxford University Press.

Ord, T. (2020). The precipice: existential risk and the future of humanity. Hachette Books.

Osman, M., McLachlan, S., Fenton, N., Neil, M., Löfstedt, R., \& Meder, B. (2020). Learning from behavioural changes that fail. Trends in Cognitive Sciences, 24(12), 969-980. https://doi.org/10.1016/j.tics.2020.09.009

Paolacci, G., \& Yalcin, G. (2020). Fewer but poorer: Benevolent partiality in prosocial preferences. Judgment and Decision Making, 15(2), 173-181. https://repub.eur.nl/pub/126676/

Patel, V., Chisholm, D., Parikh, R., Charlson, F. J., Degenhardt, L., Dua, T., Ferrari, A. J., Hyman, S., Laxminarayan, R., Levin, C., Lund, C., Medina Mora, M. E., Petersen, I., Scott, J., Shidhaye, R., Vijayakumar, L., Thornicroft, G., \& Whiteford, H. (2016). Addressing the burden of mental, neurological, and substance use disorders: Key 
messages from Disease Control Priorities, 3rd edition. The Lancet, 387(10028),

1672-1685. https://doi.org/10.1016/S0140-6736(15)00390-6

Post, S. G. (2005). Altruism, happiness, and health: It's good to be good. International Journal of Behavioral Medicine, 12(2), 66-77. https://doi.org/10.1207/s15327558ijbm1202_4

Rethink Priorities (November 10, 2021). Cognition, Welfare, and the Problem of Interspecies Comparisons. Online Panel discussion.

https://rethinkpriorities.org/cognition-welfare-and-the-problem-of-interspecies-compariso ns

Roll, J. M., Kennedy, J., Tran, M., \& Howell, D. (2013). Disparities in Unmet Need for Mental Health Services in the United States, 1997-2010. Psychiatric Services, 64(1), 80-82. https://doi.org/10.1176/appi.ps.201200071

Sassi, F. (2006). Calculating QALYs, comparing QALY and DALY calculations. Health policy and planning, 21(5), 402-408.

Schaeuffele, C., Schulz, A., Knaevelsrud, C., Renneberg, B., \& Boettcher, J. (2021). CBT at the Crossroads: The Rise of Transdiagnostic Treatments. International Journal of Cognitive Therapy, 14(1), 86-113. https://doi.org/10.1007/s41811-020-00095-2

Schleider, J. L., Mullarkey, M. C., \& Chacko, A. (2020). Harnessing Wise Interventions to Advance the Potency and Reach of Youth Mental Health Services. Clinical Child and Family Psychology Review, 23(1), 70-101. https://doi.org/10.1007/s10567-019-00301-4

Schleider, J., \& Weisz, J. (2018). A single-session growth mindset intervention for adolescent anxiety and depression: 9-month outcomes of a randomized trial. Journal of Child Psychology and Psychiatry, 59(2), 160-170. https://doi.org/10.1111/jcpp.12811 
Schneider, T., Luethi, J., Mauermann, E., Bandschapp, O., \& Ruppen, W. (2020). Pain response to open label placebo in induced acute pain in healthy adult males. Anesthesiology, 132(3), 571-580.

Schönegger, P., \& Wagner, J. (2019). The moral behavior of ethics professors: A replication-extension in German-speaking countries. Philosophical Psychology, 32(4), 532-559. https://doi.org/10.1080/09515089.2019.1587912

Schubert, S., \& Caviola, L. (2021). Virtues for Real-World Utilitarians. https://psyarxiv.com/w52zm

Schubert, S., Caviola, L., \& Faber, N. S. (2019). The Psychology of Existential Risk: Moral Judgments about Human Extinction. Scientific Reports, 9(1), 15100. https://doi.org/10.1038/s41598-019-50145-9

Schwartz, C., Meisenhelder, J. B., Ma, Y., \& Reed, G. (2003). Altruistic social interest behaviors are associated with better mental health. Psychosomatic Medicine, 65(5), 778-785.

Schwitzgebel, E., Cokelet, B., \& Singer, P. (2020). Do ethics classes influence student behavior? Case study: Teaching the ethics of eating meat. Cognition, 203, 104397.

Seabright, P. (1993). Managing local commons: theoretical issues in incentive design. Journal of economic perspectives, 7(4), 113-134.

Shapiro, I. (2017). Collusion in restraint of democracy: Against political deliberation. Daedalus, $146(3), 77-84$.

Sherman, R. A., Rauthmann, J. F., Brown, N. A., Serfass, D. G., \& Jones, A. B. (2015). The independent effects of personality and situations on real-time expressions of behavior and emotion. Journal of Personality and Social Psychology, 109(5), 872-888. https://doi.org/10.1037/pspp0000036 
Singer, P. (1979/2011). Practical ethics (3rd ed.). Cambridge university press.

Slovic, P. (2007). "If I look at the mass I will never act": Psychic numbing and genocide. Judgment and Decision Making, 2, 79-95

Snowden, J., Halstead, J., \& Hoeijmakers, S. (2019) "Mental Health Cause Area Report," Founders Pledge, retrieved from founderspledge.com/research/fp-mentalhealth

Sparkman, G., \& Walton, G. M. (2017). Dynamic Norms Promote Sustainable Behavior, Even if It Is Counternormative. Psychological Science, 28(11), 1663-1674. https://doi.org/10.1177/0956797617719950

Sparkman, G., Weitz, E., Robinson, T. N., Malhotra, N., \& Walton, G. M. (2020). Developing a Scalable Dynamic Norm Menu-Based Intervention to Reduce Meat Consumption. Sustainability, 12(6), 2453. https://doi.org/10.3390/su12062453

Spence, A., Poortinga, W., \& Pidgeon, N. (2012). The psychological distance of climate change. Risk Analysis: An International Journal, 32(6), 957-972.

Stachl, C., Au, Q., Schoedel, R., Gosling, S. D., Harari, G. M., \& Buschek, D. (2020). Predicting personality from patterns of behavior collected with smartphones. Proceedings of the National Academy of Sciences, 117(30), 17680-17687.

Stern, P. C. (2011). Contributions of psychology to limiting climate change. American Psychologist, 66(4), 303. https://doi.org/10.1037/a0023235

Stanovich, K. E., \& West, R. F. (1997). Reasoning independently of prior belief and individual differences in actively open-minded thinking. Journal of Educational Psychology, 89(2), 342. 
Stewart, R., Hill, K., Stewart, J., Bimler, D., \& Kirkland, J. (2005). Why I am a Psychology Major: An Empirical Analysis of Student Motivations. Quality and Quantity, 39(6), 687-709. https://doi.org/10.1007/s11135-005-4484-9

Tetlock, P. E. (1999). Accountability theory: Mixing properties of human agents with properties of social systems. In Shared cognition in organizations (pp. 117-138). Psychology Press.

Tetlock, P. E., \& Gardner, D. (2015). Superforecasting: The art and science of prediction. Crown Publishers/Random House.

Thaler, R. H., Sunstein, C. R., \& Balz, J. P. (2013). Choice architecture. In The behavioral foundations of public policy (pp. 428-439). Princeton University Press.

Thoits, P. A., \& Hewitt, L. N. (2001). Volunteer work and well-being. Journal of health and social behavior, 115-131.

Thornicroft, G., Chatterji, S., Evans-Lacko, S., Gruber, M., Sampson, N., Aguilar-Gaxiola, S., Al-Hamzawi, A., Alonso, J., Andrade, L., Borges, G., Bruffaerts, R., Bunting, B., Caldas de Almeida, J. M., Florescu, S., de Girolamo, G., Gureje, O., Haro, J. M., He, Y., Hinkov, H., ... Kessler, R. C. (2017). Undertreatment of people with major depressive disorder in 21 countries. The British Journal of Psychiatry, 210(2), 119-124.

Tilburt, J. C., Emanuel, E. J., Kaptchuk, T. J., Curlin, F. A., \& Miller, F. G. (2008). Prescribing "placebo treatments": results of national survey of US internists and rheumatologists. Bmj, 337.

Todd, B. (2021). One of our readers is now the richest person in the world under 30. 80,000 hours 2021-09-18 newsletter.

Trull, T. J., \& Ebner-Priemer, U. W. (2009). Using experience sampling methods/ecological momentary assessment (ESM/EMA) in clinical assessment and clinical research: 
Introduction to the special section. Psychological Assessment, 21(4), 457-462. https://doi.org/10.1037/a0017653

United Nations Secretary-General (2021) Secretary-General's remarks to the General Assembly presenting "Our Common Agenda”. Available from:

https://www.un.org/sg/en/node/258971

Urry, H. L., Lane, K. A., Calin-Jageman, R., Srivastava, S., Cheung, F., Hoeberling, K., ... Tellinghuisen, D. J. (2018, June 24). Consolidating Teaching Resources. Retrieved from osf.io/bts $5 \mathrm{~d}$

Walker, C., Donaldson, C., \& Plant, M. (2021). Problem area report: mental health. Happier Lives Institute Report. https://www.happierlivesinstitute.org/mental-health.html Last visited November 15, 2021.

Wang, P. (2019). On defining artificial intelligence. Journal of Artificial General Intelligence, $10(2), 1-37$.

Willett, W., Rockström, J., Loken, B., Springmann, M., Lang, T., Vermeulen, S., Garnett, T., Tilman, D., DeClerck, F., Wood, A., Jonell, M., Clark, M., Gordon, L. J., Fanzo, J., Hawkes, C., Zurayk, R., Rivera, J. A., De Vries, W., Majele Sibanda, L., ... Murray, C. J. L. (2019). Food in the Anthropocene: The EAT-Lancet Commission on healthy diets from sustainable food systems. The Lancet, 393, 447-492. https://doi.org/10.1016/S0140-6736(18)31788-4

Weathers, S. T., Caviola, L., Scherer, L., Pfister, S., Fischer, B., Bump, J. B., \& Jaacks, L. M. (2020). Quantifying the Valuation of Animal Welfare Among Americans. Journal of Agricultural and Environmental Ethics, 33(2), 261-282.

https://doi.org/10.1007/s10806-020-09824-1 
Weinstein, N., \& Ryan, R. M. (2010). When helping helps: autonomous motivation for prosocial behavior and its influence on well-being for the helper and recipient. Journal of personality and social psychology, 98(2), 222. https://psycnet.apa.org/record/2010-00584-005

Wergeland, G. J. H., Fjermestad, K. W., Marin, C. E., Haugland, B. S.-M., Bjaastad, J. F., Oeding, K., Bjelland, I., Silverman, W. K., Öst, L.-G., Havik, O. E., \& Heiervang, E. R. (2014). An effectiveness study of individual vs. Group cognitive behavioral therapy for anxiety disorders in youth. Behaviour Research and Therapy, 57, 1-12. https://doi.org/10.1016/j.brat.2014.03.007

Wiblin, R. (2016, April). How can you figure out which global problem is most pressing? 80,000 Hours. https://80000hours.org/articles/problem-framework/

Wild, M. (2019). Tierphilosophie zur Einführung. Junius Verlag.

Wilks, M., Caviola, L., Kahane, G., \& Bloom, P. (2021). Children Prioritize Humans Over Animals Less Than Adults Do. Psychological Science, 32(1), 27-38. https://doi.org/10.1177/0956797620960398

Wolfers, J., \& Zitzewitz, E. (2004). Prediction markets. Journal of economic perspectives, 18(2), $107-126$.

Wynes, S., \& Nicholas, K. A. (2017). The climate mitigation gap: Education and government recommendations miss the most effective individual actions. Environmental Research Letters, 12(7). https://doi.org/10.1088/1748-9326/aa7541

Yudkowsky, E. (2008). Cognitive biases potentially affecting judgment of global risks. Global catastrophic risks, 1(86), 13. 
Zhou, E. S., Hall, K. T., Michaud, A. L., Blackmon, J. E., Partridge, A. H., \& Recklitis, C. J. (2019). Open-label placebo reduces fatigue in cancer survivors: a randomized trial. Supportive Care in Cancer, 27(6), 2179-2187. 